\title{
Ranjana Numeral System: A Brief Information
}

\author{
Eka Ratna Acharya \\ Central Department of Education, University Campus, Tribhuvan University, Kathmandu, Nepal \\ Corresponding author:er47acharya@gmail.com
}

Received: Dec 5, $2017 \quad$ Revised: Dec 15, $2017 \quad$ Accepted: Dec 20, 2017

\begin{abstract}
The Ranjana script, which is also known as Kutila or Lantsa, is one of the many alphabets derived from the Brahmi script. This numesmetic inscription was developed 2216 years ago, so its time period was along the $199 \mathrm{BC}$ and it was popular from 11th century AD and was used until the mid-20th century in Nepal and India. It is popularly used by Nepali in the Newari language. This script also known as Lantsa, for writing the Sanskrit titles of books which have been translated from Sanskrit to Tibetan for decoration in temples and mandalas. There were few texts printed with alternating lines in Sanskrit in the Lantsa script followed by a Tibetan translation. There were many original Sanskrit manuscripts written in Lantsa preserved in Newar community in Nepal. Others were destroyed lack of its preservation. In addition, the Ranjana script was used mainly for decoration by Buddhists.
\end{abstract}

Key words: Nepal, Newari, Ranjana, Brahmi, Numerals

\section{Introduction}

Ranjana numeral system developed in 199 BC is the Nepali numeral system. It is popular in Nepal Bhasha language (Newari language). Suipunawal Group, Sankhu published a booklet describing the primary phases of history of Nepal [6]. In this small treatise this group explained the Nepal and Nepali inhabitants. They described that, in the lap of the large Himalaya Ranges a land of the name 'Nepal' was established nearly 4, 80, 00000 years ago which was under the Tethys Sea. They also described the fossils of Ramapithecus found at Tinau River at Butwal of Nepal. This area is near the Lumbini, Birth place of Siddhartha Gautama Buddha.

Here the writer's concern is to explore the Ranjana numerals and its importance. These numeral system gives the Nepal's own scenario in the field of numeral systems. Ranjana script was recorded in United Nation's record [2]. This is the single script that written with Gold in the Pragyaparmita contains 2,032 pages with 4 volumes [2]. It contains the Ranjana numeral system. Perhaps it is the largest treaties in the language script in the world. Type of writing system: syllabic alphabet-each letter has an inherent vowel (a). Other vowels can be indicated using a separate letters or diacritics. Direction of writing: left to right in horizontal lines. As well as the Ranjana script, Nepal Bhasa has been written with the Brahmi, Gupta, Prachalit, Bhujimol and Devanagari script.

This numeral system is related with Brahmi numerals system. The Brahmi numerals systems was developed $3^{\text {rd }}$ century BC. The Brahmi numerals were seen in Ashoka pillar in Lumbini of Nepal. 
The Ranjana script, which is also known as Kutila or Lantsa, is one of the many alphabets derived from the Brahmi script [3]. It was developed during the time period of Brahmi script.

\section{Illustration of Development of Ranjana Numeral System}

Nepali and Tibetans were used this script, which they call Lantsa, for writing the Sanskrit titles of books that have been translated from Sanskrit to Tibetan. It was used for decoration in temples and mandalas. There are also a few texts printed with alternating lines in Sanskrit in the Lantsa script followed by a Tibetan translation. There were many original Sanskrit manuscripts written in Lantsa preserved in the old monasteries of Tibet but most of these were destroyed. In addition, the Ranjana script was also used mainly for decoration by Buddhists in China, Mongolia and Japan.

Among the different scripts based on Nepali script, Ranjana ("delightful"), Bhujimol ("fly-headed") and indigenous ("ordinary") are the most common. Ranjana is the most ornate among the scripts. It is most commonly used to write Buddhist texts and inscribe mantras on prayer wheels, shrines, temples, and monasteries. The popular Buddhist mantra Om Mani Padma hum ("Hail to the jewel in the lotus") This is in Sanskrit based mantra which as often written in Ranjana. The following photograph illustrate the numeral systems. This photograph contains two types of numerals, the numerals which are in upper part of this photograph are Lichhavi numerals and the numerals in the lower part of this photograph are Ranjana numerals. The second photograph contains the Ranjana alphabetical letters $[4,6]$.

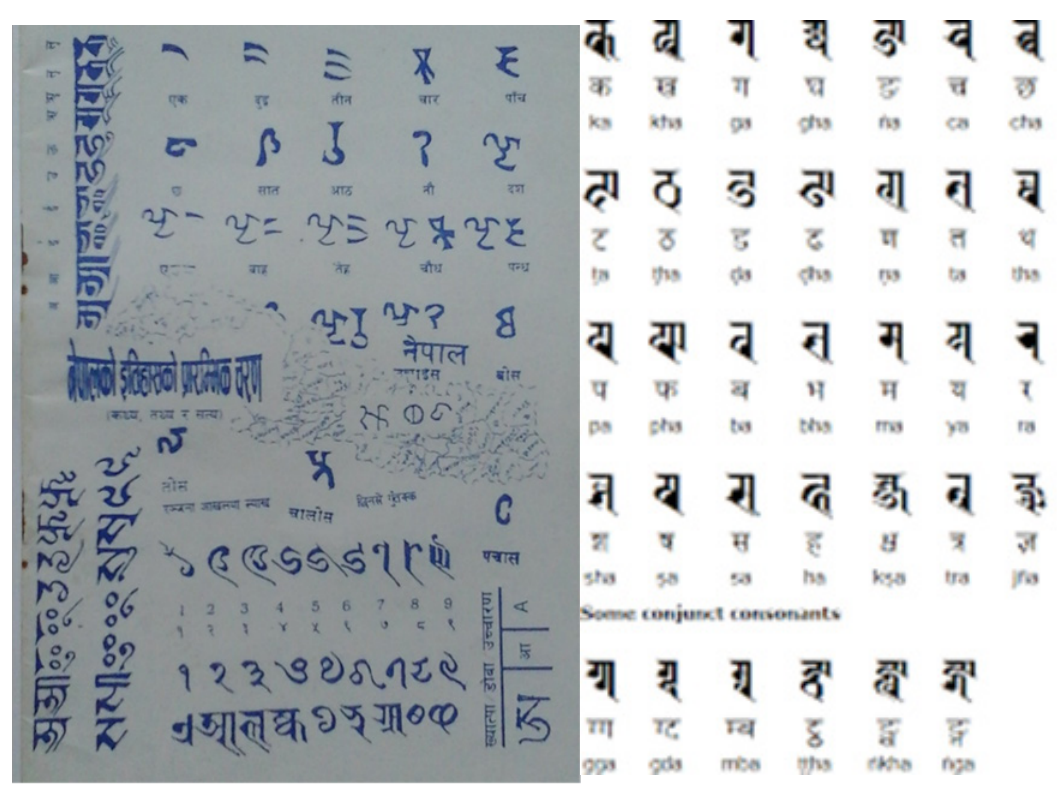

Fig. 1: Ranjana Inscription and Ranjana Numerals-1

These symbolic photographs are not newly created, these are existed early which whispered for general known. The following photograph illustrate the Ranjana numerals with zero. The numerals zero (0) was popularly used but about its developments only the different assumptions were appeared. Here this photograph contains the symbol of a numeral zero (0). Here it explore a mystery that Ranjana numeral system has contribution to the development of symbol of zero! It is another part of research. This is the views of this paper's writer on the basis of existing documents [4]. 


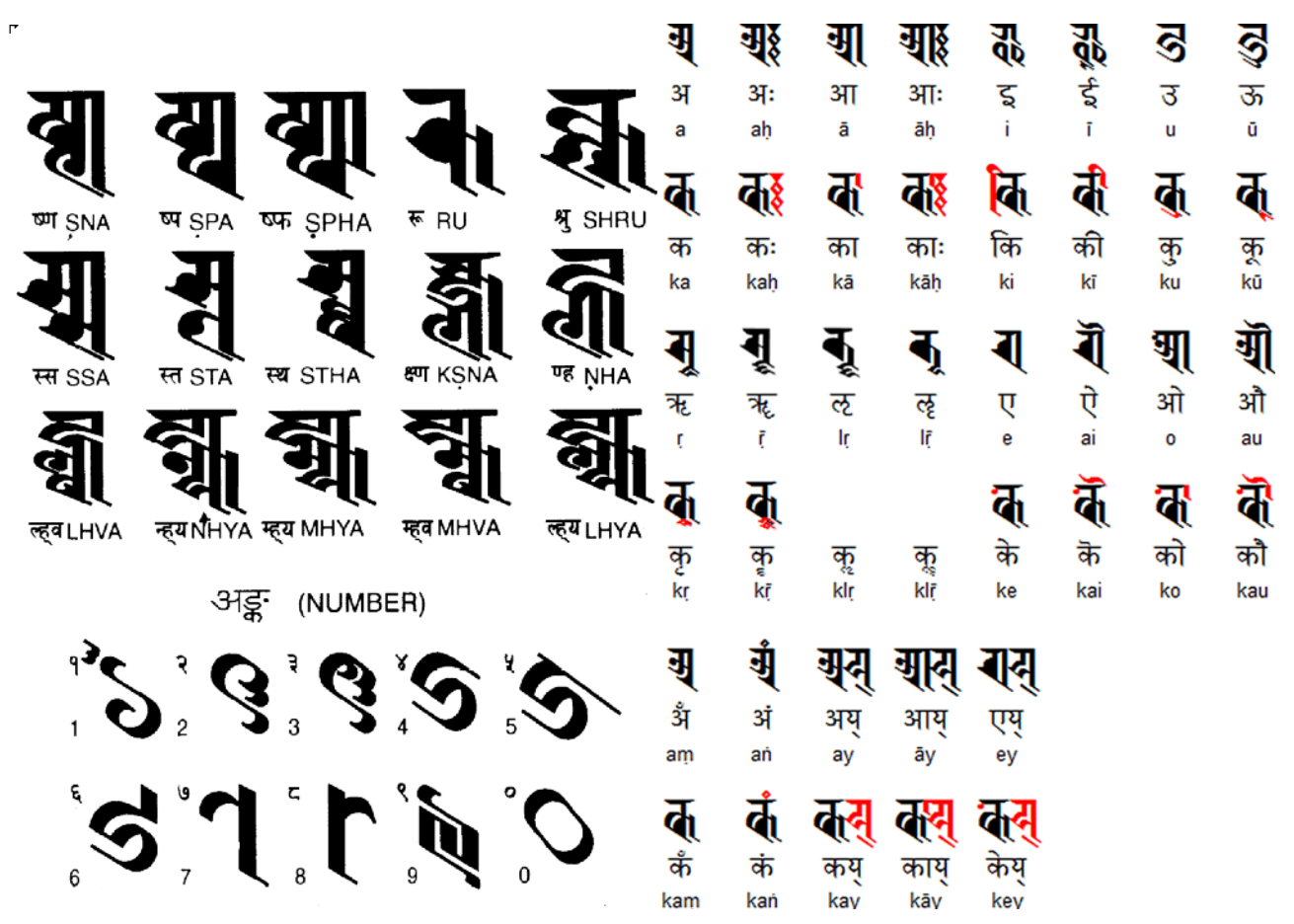

Fig. 2: Ranjana Inscription and Ranjana Numerals-2

\section{Characteristics of Ranjana Numeral System}

Ranjana numerals were developed with Ranjana script. It also contains symbol of zero. It is parallel product of Brahmi and Lichhavi numerals systems especially in Nepal. It is very near to other scripts like Sanskrit and Devanagari inscriptions. The Notable features of Ranjana inscription and numeral system are listed below.

(i) Type of writing system: syllabic alphabet-each letter has an inherent vowel (a). Other vowels can be indicated using a separate letters.

(ii) Direction of writing: left to right in horizontal lines.

(iii) It contains the symbols of zero (0).

(iv) It is Nepal's indigenous developments in the field of numeration system and hence is as the fundamental elements of mathematics developments.

(v) It impacts the neighbors to develop the script of language.

(vi) It gets the warm lap of one of the large script system 'Ranjana Script'.

\section{Changes of Numeral System}

We see that the numerals were developed from many changes in different phases of times. So the Ranjana numerals having the 2216 years long time line it crossed the many process of ascending (arohan) and descending (awarohan) pertains to the awakening of reality of this phase. This expression was found in a dissertation of review of classical mathematics in Nepal [1]. The variation of numerals system is illustrated by Shreshtha [5]. 


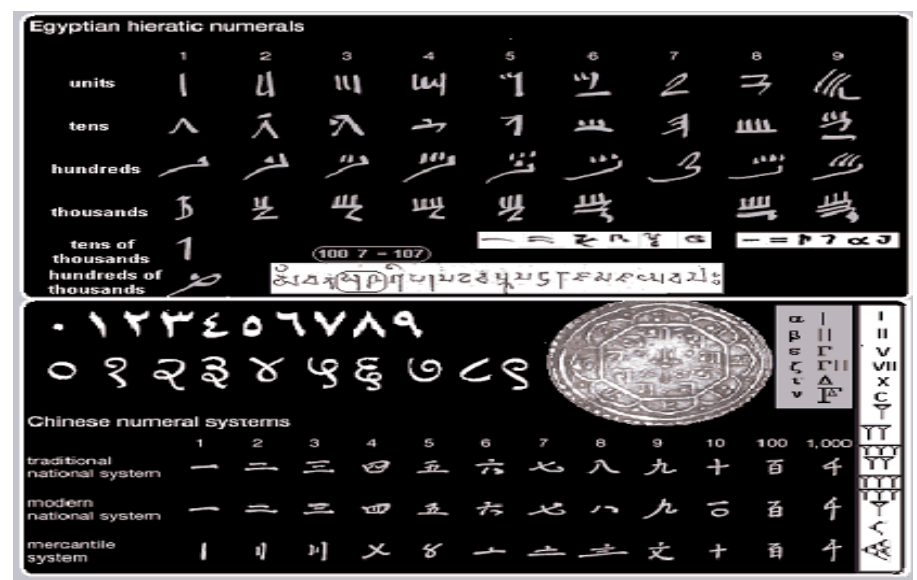

Fig. 3: Variation of Numerals

\section{Conclusion}

Nepal Bhasa (Newari), a member of the Tibeto-Burman group of Sino-Tibetan languages spoken in Nepal, India, Sikkim and West Bengal, and Bhutan by about 800,000 people. As well as the Ranjana script, Nepal Bhasa has been written with the Brahmi, Gupta, Prachalit, Bhujimol and Devanagari script used to write Sanskrit, the classical language in Bharatavarsa. Ranjana numeral system's origin is in Nepal with Nepal Bahasa. It contains 10 numerals with the symbols of zero (0). Perhaps Ranjana numeral system occupied the lap of the largest script Ranjana in Language script that focus its importance.

Acknowledgement: I wish to very sincerely thanks Prof. Christos Kourouniotis, University of Crete, Greece; Prof. Ram Man Shreshtha and Associate Prof. Dr. Gyan Bahadur Thapa (Institute of Engineering, Tribhuvan University, Nepal) for their academic supports and encouragements. Also, I am thankful to the EU Erasmus Mundus, LEADER Project for post doctoral funding to carry out the work at University of Crete, Greece in 2017/18.

\section{References}

[1] Acharya ER (2015), Naya Raj Pantaka Ganitiya Kritiharuko Adhyayan. Unpublished PhD Dissertation, Nepal Sanskrit University, Dang, Nepal.

[2] Neupane D (Sep 8, 2017), Nepal got the membership of United Nation in the help Assistance of The 2216 years earlier written Nepal Bhasha's treaties but! Kantipur: Kantipur Publication.

[3] Pant DR (2015), Writings of Numerals System in Nepal in Ancient Times, Journal of Mathematics Education, 1(1) : 65 - 66.

[4] Ranjana Script: http://www.omniglot.com/writing/ranjana.htm (Retrieved 11/12/2017).

[5] Shreshtha RM (2008), Mathematics Education For The Twenty First Century, New Nepal, Kathmandu: Nepal Academy Of Science And Technology.

[6] Suipunawal Group (2001), Sankhu, Kathmandu: Suipunawal Group. 